\title{
Colesevelam Hydrochloride
}

National Cancer Institute

\section{Source}

National Cancer Institute. Colesevelam Hydrochloride. NCI Thesaurus. Code C28937.

A hydrochloride salt form of colesevelam, a non-absorbed polymer that binds bile acids in the intestine and lowers serum lipids. 